\title{
Needs assessment of emergency medical and rescue services in Abuja/Nigeria and environs
}

\author{
Peter Asaga Mac ${ }^{1,2^{*}}$, Axel Kroeger ${ }^{1}$ and Philomena Ehi Airiohuodion ${ }^{3}$
}

\begin{abstract}
Background: Nigeria is ranked second highest in the rate of road accidents and other emergencies (Deaths, disabilities) among 193 countries of the world. There is therefore the need for analyzing Emergency Medical Rescue Services (EMRS) in the country to identify options for improvement.

Method: The study was conducted from February, 2016 to March, 2017 in three EMRS organizations (FRSC, NEMA and MAITAMA Hospital) located in Abuja. The structure, resources, process of EMRS activities and outcome (delay times, case fatality as well as victims and service-providers satisfaction with services) were assessed through observation, time measurements and interviews.

Results: FRSC and NEMA offers (Road Traffic Injury) RTI and Disaster services, the ambulances consist of Intensive Care Unit(ICU) buses, Helicopters, Speed boats, motorbikes and other specialized vehicles. Mortality and morbidity recorded for 2016 was 1.1 and $2 \%$ respectively. MAITAMA is a specialist centre that offers general medical services. A total number 1227(88.8\%) lives were saved during the observational period by three organizations, 60(4.9\%) deaths, 132 (9.6\%) disabilities, 793 (57.2\%) NCDs and 593(42.8\%) RTI.

Conclusion: Non-communicable diseases (NCDs) cause many deaths and morbidities in the developing world compared to infectious diseases. There is need for total revamping and education of EMRS institutions in Nigeria and Low- Middle Income Countries (LMICs). Abuja and its surroundings suffers from delays in rapid emergency services, lack of adequate awareness, functional ambulances, minimal specialists and inadequate consumables lead to the loss of many lives.
\end{abstract}

Keywords: Emergency medical rescue services (EMRS), Delay times, Abuja, Road traffic injury (RTI), NEMA, FRSC, MAITAMA

\section{Background}

The three fundamental functions of a health system are to improve the health of the population, respond to people's expectations, and provide financial protection against the costs of ill-health [1,2]. Emergency medical care can contribute positively to these functions. There are no empirical data on the number of lives or disability-adjusted life-years (DALYs) saved

\footnotetext{
* Correspondence: pasaga123x@gmail.com;

asaga.peter@student.unifreiburg.de

${ }^{1}$ Centre for Medicine \& Society (Global Health), University Medical Centre

Freiburg, 79014 Freiburg, Germany

${ }^{2}$ Institute of Human Virology, University Medical Centre Freiburg, Freiburg,

Germany

Full list of author information is available at the end of the article
}

through emergency medical care [2-4]. Nevertheless, many of the conditions that contribute to the burden of disease in Nigeria and other low-income countries can be mitigated through prompt treatment [5-7]. Enhancing a health system's responsiveness to people's expectations leads to improved utilization of services and better outcomes [1, 8]. Access to medical care for urgent or life threatening conditions is a key expectation in many communities in Nigeria [9-11]. In response to this, two major institutions were created in addition to the existing emergency departments in the major governmental hospitals. These are:

C The Author(s). 2019 Open Access This article is distributed under the terms of the Creative Commons Attribution 4.0 International License (http://creativecommons.org/licenses/by/4.0/), which permits unrestricted use, distribution, and 


\section{Federal Road Safety Commission (FRSC)}

The Federal Road Safety Commission (FRSC) was established in 1988. The agency is the lead organization in Nigeria on road safety administration and management and has offices in all States of the country. The statutory function of the agency includes; making the highways safe for motorist and other road users; checking road worthiness of vehicles; recommending works and infrastructures to eliminate or minimize accidents on the highways and educating motorists and members of the public on the importance of road discipline on the highways [12]. It has vehicle ambulances equipped with medical gadgets and devices. FRCS has a call centre with a unique number which is toll free. The services are free of charge.

\section{National Emergency Management Agency (NEMA), Abuja Nigeria}

NEMA was established in the year 1999, and is saddled with the responsibility of managing medical emergencies such as fire outbreaks, disease epidemics, flood disasters and road traffic accidents $[13,14]$. It is a federal government agency that is promptly mobilized during disasters and other medium scale emergencies. The agency is equipped with modern emergency combating gadgets such as Helicopter; Vehicle and Boat ambulances. NEMA has a call centre with a national emergency number which is $24 \mathrm{~h}$ toll free. The agency also has Beacon services (a tracking transmitters, which is triggered during an emergency). The basic purpose of this system is to help rescuers find survivors within the so-called "golden day"(the first $24 \mathrm{~h}$ following a traumatic event) during which the majority of survivors can usually be saved. The ambulance services are free of charge. The agency has offices located in the 36 states of the Federal Republic of Nigeria.

\section{MAITAMA hospital Abuja}

The Hospital is located along Aguyi Ironsi Way, Maitama district, Abuja. It is one out of the many federal government owned tertiary care medical centres with the responsibility of providing general medicine and specialized services. The medical team includes 15 medical consultants in various fields of medicine including accident and emergencies (A\&E). It has a well-functioning unit of accident and emergency care, with vehicle ambulances equipped with medical equipment and first aid devices [15]. The accident and emergency unit call centre is called" Compound Unit" which operates a 24-h service. Their emergency number is different from those of the other institutions. The three institutions work synergistically. The purpose of this study is to analyse different aspects of the medical emergency system in Abuja and Keffi in order to identify possible weaknesses and limitations which could be corrected by policy decisions and practical actions in order to make the life safer for the local population.

\section{Methods}

This study was conducted in Abuja federal capital territory and Keffi area council of Nasarawa state. Abuja is the federal capital and the seat of federal government of Nigeria. It has a total population of 3.4 million people and an area of $1769 \mathrm{~km}^{2}$ with a population density of 698.6 inhabitants $/ \mathrm{km}^{2}[16]$.

\section{Documentation of published and unpublished materials} An analysis of locally available documents and a literature review was done to get information on the burden of medical emergencies dealt with by FRSC, NEMA and MAITAMA hospital. A literature review on relevant information on medical emergencies with a focus on low income countries was done. Publications were identified through search engines; unpublished material included hospital and EMRS booklets, files and other records in the three institutions. Photos were taken during the field visits to the EMRS agencies and rescue operations.

\section{Qualitative methods}

Focus Group discussions (FGDs) with EMRS providers (mainly paramedics, nurses and doctors) and organizers (mainly team managers and administrative staff) were conducted, one FGD for each organization with about 10 participants in each group. Personal interviews (both semi-structured questionnaires and in-depth interviews) were conducted by the Principal Investigator (PI) and trained interviewers with 1500 victims and/or their relatives. Furthermore, in-depth interviews were conducted by the PI with heads of three main agencies offering EMRS (NEMA, FRSC, and MAITAMA Hospital).

\section{Participant observations, interviews and time measurements (qualitative/ quantitative)}

Measurements of delay times were carried out (from receiving the emergency call to attending to the patient in the emergency ward) by the principal investigator by accompanying for 2 weeks the emergency team/staff of three institutions, observing their activities while rescuing victims and measuring of the delay times between call and arrival at scene. Also, the activities of the Bay Post staff were observed using an observation list (A Bay post is a road side building that houses emergency ambulances and personnel, located every $17 \mathrm{~km}$ along major roads in Abuja; see below). At the Call Centres interviews were conducted and forms were checked to document the number of calls per shift. Participant observations were made during and after the rescue operations regarding people's awareness of the emergency 
system. The EMRS Basic equipment in ambulance services were observed and documented.

\section{Questionnaire survey and data analysis}

A questionnaire with closed and open-ended questions was applied to EMRS users and providers to extract information on the quality of EMRS activities as perceived by victims, their relatives and emergency care providers. It included questions on the frequency of EMRS refresher training courses for improving skills in Basic Life Support (BLS), Advanced Cardiac Life Support (ACLS) and Advanced Trauma Life Support (ATLS). Responses to the closed questions were entered into the computer and analysed with SPSS package producing descriptive statistics. Responses to open ended questions were transcribed and analysed using categorical evaluation.

\section{Ethical considerations/statement}

The research study was conducted in compliance with the ethical principles of the Nuremberg Code and the Declaration of Helsinki (BMJ, 1996; WHO, 2001). The research protocol was submitted and approved by the Ethical Committee of the University of Freiburg (approval number 171/17) which was accepted by the Nigerian authorities. Written informed consent was obtained from all study participants.

\section{Results}

Table 1 summarizes the findings of the document analysis of the three EMRS organizations in Abuja/ Keffi. It shows that FRSC is responsible for rescue operations related to traffic accidents, NEMA for natural disasters and MAITAMA for general medical emergencies. The staff numbers are highest in FRSC with 19,000 employees in the whole country most $(64.7 \%)$ of them being males, second NEMA with 700 employees, predominantly males $(64.7 \%)$, and third MAITAMA where most of the 762 staff were nurses (72.3\%). The emergency transport system of the 3 EMRS organizations were well coordinated, equipped with most of the basic emergency rescue equipment. Rescue services are free and funded by the government.

The information was obtained in the three call centres; observations were made in 6 Bay posts, 32 ambulances and 2 boats. i) The Bay-Post system: Road safety in Abuja and Keffi is largely offered by Bay posts. These are road side buildings located every $17 \mathrm{~km}$ along the major roads in Abuja and other cities in Nigeria. Bay posts (see photo) have ambulance buses and motorbikes equipped with Intensive Care units (ICU). The staff of a Bay post includes Paramedics and Nurses (Table 2). Bay posts are operated by NEMA and FRSC but not by MAITAMA. When an emergency call is received by the call centre, the operator will alert the closest Bay post to the scene to deploy ambulances. FRSC and NEMA have a total of 23 Bay Posts located within and on the outskirts of Abuja/Keffi. MAITAMA has no bay post but a total of 25 staff at the call centre, known as the "compound unit".

ii) The ambulance services: Ambulances used by FRSC were mainly ICU buses. NEMA has specialized ICU vehicles, 4 helicopters and 10 Boats for the riverine emergency bay post units. MAITAMA has less ambulance buses as most of them were grounded. All emergency victims and their relatives were conveyed to the final care facility by the organizations ICU ambulances. FRSC and NEMAICU ambulances were equipped with oxygen tanks and a few consumables (for example oxygen supply gear, gloves, shears, bandages, hand gloves, ECG monitoring machine, extraction machine, BCLS and ACLS equipment). Each ambulance bus takes up to 4 patients. MAITAMA ambulances lack extraction equipment. NEMA is the only EMRS organization with operational helicopters and boats, FRSC has helicopters but they are not functional, as these are grounded because of limited manpower and technical faults. FRSC and NEMA have 200 motorcycles operating $24 \mathrm{~h}$ a day and 7 days a week on the roads and suburbs of Abuja. NEMA has ambulance boats operating along the river that runs through and out of Abuja. (The Abuja River is a recreational spot, and it is also where the great water work of Abuja is located, supplying the city with water). The boats have basic emergency life support equipment. The hospital in MAITAMA runs seven ambulance buses. There are 21 additional buses, but they are grounded which

Table 1 Resources and main services of the three institutions In Nigeria (2016). Equipment and staffing of Bay posts, ambulances and boats

\begin{tabular}{|c|c|c|c|c|c|c|}
\hline INST/ORG & FOUNDING & SERVICES & AMBULANCE & NO OF & FF AND \% GEND & ISTRIBUTION \\
\hline FRSC & 1988 & Road safety & ICU Buses & 19,000 & Female (35.3\%) & Male $(64.7 \%)$ \\
\hline NEMA & 1999 & $\begin{array}{l}\text { Disaster } \\
\text { Mgt. }\end{array}$ & ICU Buses, Helicopters, Boats, motorbikes. & 700 & Female (35.3\%) & Male $(64.7 \%)$ \\
\hline MAITAMA & 2001 & General health services. & ICU Buses & 762 & Female $(72.3 \%)$ & Male $(27.7 \%)$ \\
\hline
\end{tabular}


Table 2 Resources of rescue services and capacity building (Information from heads of EMRS Organizations in Abuja)

\begin{tabular}{|c|c|c|c|}
\hline Item & FRSC & NEMA & MAITAMA \\
\hline Number of Call Centres & 1 & 1 & 1 \\
\hline No of Ambulances \& other vehicles. & $\begin{array}{l}8 \mathrm{ICU} \\
\text { Buses }\end{array}$ & $\begin{array}{l}\text { ICU 8, Special ICU Vehicles 8, Helicopters 4, Boats, } \\
10\end{array}$ & $\begin{array}{l}7 \text { ICU functional ambulances ( } 21 \\
\text { grounded) }\end{array}$ \\
\hline No. of Bay post & 13 & 10 & 0 \\
\hline No. of staff per Bay post & 10 & 20 & 25(only at call Centre) \\
\hline $\begin{array}{l}\text { EMRS Basic equipment in } \\
\text { ambulances }\end{array}$ & $7 / 8$ & $30 / 30$ & $7 / 7$ \\
\hline No. and $\%$ of trained staff/year & $1(10 \%)$ & $6(30 \%)$ & $4(8 \%)$ \\
\hline Staff with Trained skills in ACLS, ATLS & $5(50 \%)$ & $7(35 \%)$ & $4(16)$ \\
\hline
\end{tabular}

ACLS: Advance cardiac life support machine

ATLS: Advance trauma life support machine

BLS: Basic life support machine

ICU: Intensive care unit

limits the organizational effectiveness in response to emergencies.

iii) Ambulance staff: Each ambulance bus from FRSC and NEMA has a nurse and 3 paramedics when embarking on an emergency rescue. MAITAMA hospital has a complete team, made up of 1 doctor, 3 nurses and 2 paramedics. These are qualified staff in advanced cardiovascular life support (ACLS), which refers to a range of clinical interventions for the urgent treatment of cardiac arrest, stroke and other life- threatening medical emergencies; they also have the knowledge and skills to deploy advanced trauma life support (ATLS). However, there was a shortage of staff training: The total number of staff trained annually in emergency courses, workshops and seminars varies among the three organizations, as indicated in Table 2; 10\% of the personnel from FRSC, 30\% from NEMA and 8\% of the staff from MAITAMA received such training during the last 12 months.

iv) Cost of services: Although the emergency services rendered are free of charge, the victims or relatives pay for consumables and blood. The cost is between150-400 Euro depending on the nature of the emergency and the organization involved in the rescue mission. This information was obtained from the heads of the three EMRS organizations.

\section{Magnitude of medical emergencies and response by EMRS organizations}

The documented amount of rescue operations carried out by FRSC and MAITAMA are shown in Fig. 1: approximately 13,600 to 13,700 operations in 2016; NEMA had a lower workload with less than 3000 operations (Fig. 1). The highest case fatality rate (CFR) occurred in traffic injuries $(25.5 \%$ of all accidents), less in clinical emergencies $(5.4 \%)$ and natural disasters $(1.3 \%)$. The proportion of disabilities caused by traffic injury in FRSC
(57\%) was also higher than those by other medical emergencies (9\% medical emergencies in MAITAMA and $30 \%$ in NEMA).

The magnitude of medical emergencies and outcomes during the 14-days observation period

The magnitude of medical emergencies and outcome during the 14-days observation period in each institution Table 3 presents the activities observed by the 3 organizations regarding the number of calls, types of emergencies, number of lives saved, number of deaths and disabilities assessed during the 14-day observational study. It shows a high workload of 1000 calls a day in MAITAMA hospital mainly non - communicable diseases (stroke and other cardiovascular disease [CVDs], diabetic coma, snake bites) and a smaller number of road traffic injuries (RTIs). All calls at FRSC (192 per day) were related to RTIs and to a lesser extent to other medical emergencies. NEMA responded to an average of 87 NCD calls per day and to fewer RTI calls. The deaths in FRSC (3.6\% fatality of all calls) were the lowest compared to higher fatalities in MAITAMA (4.1\%) and NEMA (8\%).

A total of 1386 emergencies occurred during the observation period, $1227(88.5 \%)$ lives were saved in the three organizations during the 14-day observation period, 60(4.9\%) deaths were recorded, 132(9.6\%) disabilities, 793(54.4\%) were non- communicable diseases and 593(42.9\%) were RTIs.

\section{Delay times of pre-clinical care ("transport delay"from call to arrival of ambulance at scene)}

The speed of rescue services is crucial for the survival of the patient and the delay between accident/rescue-event and arrival of the rescue team or transport to specialized treatment in hospitals should be $15 \mathrm{~min}$ or less [1]. 


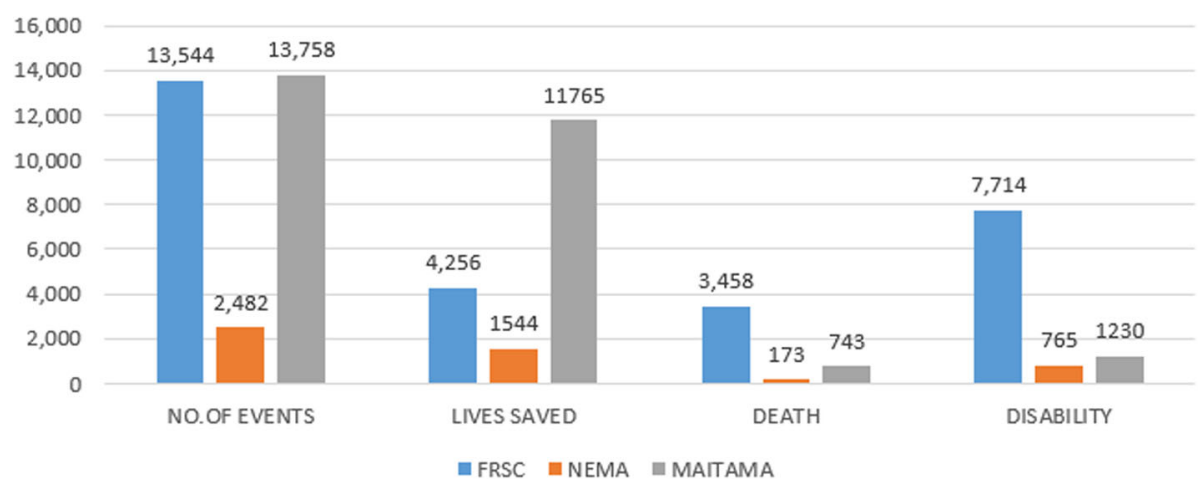

Fig. 1 The magnitude of medical emergencies and rescue results (document analysis)

Table 4 shows the average delay times observed during the observation period of 14 days. The delay times from point of call to arrival at the scene ("transport delay") for MAITAMA and NEMA were $15-30 \mathrm{~min}$, FRSC delay times were much longer (over $35 \mathrm{~min}$ ). FRSC is the agency responsible for RTIs, which often occur at the outskirts of Abuja. It is imperative (as explained by the heads of the various EMRS organizations) that emergency rescue victims from FRSC and NEMA are conveyed to MAITAMA hospital at most instances because it is a government institution, with a well-trained team.

\section{Activities of rescue staff at scene of emergency}

First aid activities carried out by EMRS staff of the 3 institutions at the scene include the administration of analgesic or pain killers, the arrest and stitching of wounds, the extraction of victims or dead bodies (mostly by FRSC and NEMA, but not by MAITAMA). Painkillers and other medicines are administered, an oxygen mask is placed on the face of the victim when the patient cannot breathe properly and the heart rate and volume are monitored using the ECG machine in the ambulance. MAITAMA has a clock which is placed in the ambulance to monitor time of arrival at scene and arrival time at the hospital for effective time management and disciplinary action in case of late arrival by the emergency team. The victim is finally transferred by means of a hospital stretcher or in some instances carried to the emergency unit, where care and management is given to the patient.

\section{Opinions of users on EMRS services and "call delays"}

Figure 2 shows that the majority of users knew about EMRS and emergency call numbers. Some of the victims, however, were unaware that such services existed, mainly victims coming to Abuja from other cities or states. Others mentioned in the interviews that they were concerned about potential treatment costs. One issue mentioned was that there was no unique call number and as a result it was difficult to identify the right number promptly, thus, the "call delays" (from start of the event until calling the emergency services). Furthermore, interference in telecommunication lines made it difficult to get through to the call centres.

Satisfaction regarding EMRS rendered by the three organizations were low for FRSC and MAITAMA, 23 and $36 \%$ respectively. However, satisfaction with NEMA services was quite high (70\%). The delay times until arrival of the rescue team, insufficient supplies and medications were frequently mentioned as a cause of dissatisfaction. Victims who used MAITAMA hospital ambulances also mentioned the lack of health insurance for EMRS victims. FRSC and NEMA services are free, but users are charged for the treatment at MAITAMA hospital. Most users said that they prefer to use the services of the few private EMRS centers in Abuja in comparison with government services because of dissatisfaction with the

Table 3 EMRS and outcomes in two weeks observation period

\begin{tabular}{|c|c|c|c|c|c|c|c|c|}
\hline \multirow{2}{*}{$\begin{array}{l}\text { INSTITUTION } \\
\text { /ORGANIZATION }\end{array}$} & \multirow[t]{2}{*}{ NO.OF CALLS PER DAY } & \multicolumn{3}{|c|}{ TYPE OF EMERGENCY } & \multirow[t]{2}{*}{ TOTAL NO. OF EMRS } & \multirow{2}{*}{$\begin{array}{l}\text { L IVES } \\
\text { SAVED }\end{array}$} & \multirow{2}{*}{$\begin{array}{l}\text { DEATHS } \\
\text { (\%) } \\
\text { (CFR) }\end{array}$} & \multirow{2}{*}{$\begin{array}{l}\text { DISABILITY } \\
(\%)\end{array}$} \\
\hline & & $\mathrm{NCD}$ & RTI & OTHER & & & & \\
\hline FRSC & $80-192$ & 2 & 190 & - & 192 & 125 & $7(3.6 \%)$ & $17(8.9 \%)$ \\
\hline NEMA & $50-87$ & 84 & 3 & - & 87 & 75 & $7(8 \%)$ & $5(5.7 \%)$ \\
\hline MAITAMA & $500-1107$ & 707 & 400 & - & 1107 & 1027 & $46(4.1 \%)$ & $110(9.9 \%)$ \\
\hline TOTAL & 1386 & 793 & 593 & & 1386 & 1227 & $60(4.8 \%)$ & $132(10.8 \%)$ \\
\hline
\end{tabular}

*Case Fatality rate (CFR) 
Table 4 Response time (in minutes) from the event to rescue to clinical care in Abuja as measured during 14 days in each institution

\begin{tabular}{|c|c|c|c|c|c|c|c|}
\hline \multirow[t]{2}{*}{ INSTITUTION } & \multirow{2}{*}{$\begin{array}{l}\text { AMBULANCE } \\
\text { TYPE }\end{array}$} & \multicolumn{4}{|c|}{ EMERGENCY TYPE NO.\& GENDER OF VICTIMS } & \multirow{2}{*}{$\begin{array}{l}\text { DEATHS } \\
\text { (CFR) }\end{array}$} & \multirow{2}{*}{$\begin{array}{l}\text { RESPONSE } \\
\text { TIME } \\
\text { (Average } \\
\text { Mins). } \\
( \pm \text { SD) }\end{array}$} \\
\hline & & TOTAL M F & & & & & \\
\hline FRSC (VR) & ICU BUS & RTA & 192 & 50 & 142 & $7(3.6 \%)$ & $35( \pm 7)$ \\
\hline NEMA (VR) & ICU/SP.BOAT & NCD/RTA & 84 & 34 & 50 & $7(8.3 \%)$ & $16( \pm 7)$ \\
\hline MAITAMA (VR) & ICU BUS & NCD/RTA & 1107 & 300 & 807 & $46(4.2 \%)$ & $15( \pm 7)$ \\
\hline
\end{tabular}

${ }^{*}$ Case Fatality rate (CFR)

latter, in particular the question of responsiveness and staff attitude. Very few victims or relatives came by private cars or taxis.

\section{Discussion}

Pre-clinical care is an integral part of a national health care system [17]. In this study we quantified the burden of medical emergencies (morbidity and case fatality) in Abuja/Keffi, the existing EMRS using input, process, output and outcome indicators and identify options for improvement (Gap Analysis). This is the first study (public or private) to be carried out in Nigeria on emergency medical rescue services, considering the 6 key medical emergency stages [18-20].

\section{EMRS burden (document analysis and observation)}

An enormous frequency (incidence) of emergencies was documented in 2016 with a case fatality of $3.5 \%$ for FRSC, 1.1\% for NEMA and 3\% for MAITAMA hospital, showing the highest figures for RTIs which is in line with other studies [16, 21]. However, a total of 1227 out of $1386(88.5 \%)$ lives were saved by the 3 organization during the 14-days observation period in the 3 institutions.

\section{Emergency response (observation study)}

During the observation study period using the 6 key stages of emergency, it was observed that nearly $90 \%$ of victims were brought within the first hour from the start of the emergency event to the hospital in spite of traffic congestion. This is still a long time for most victims but it is a substantial improvement compared to previous times. In the 1990s in Nigeria, private ambulances were mostly involved in EMRS services and 94\% of all transports had long delays [8, 22, 23]. Currently, almost all emergency transport services are rendered by public ambulances often at reasonable speed.

In this study, we distinguished between "call delay" (from occurrence of the event until calling the call centre) and "transport delay" (from receiving the call at the centre to arriving at the hospital/health care facility). The call delays were obtained through observational periods and interviews with victims. It was noticed in the interviews that long call delays were due to possible treatment costs, lack of a unique emergency number and communication/network interferences which made it difficult to get through to the call centre. Many of victims interviewed were not sure which of the 3 EMRS organizations to call and their various roles and functions leading to extended call delays. The "transport delay" (from call to the rescue team arriving at scene with first

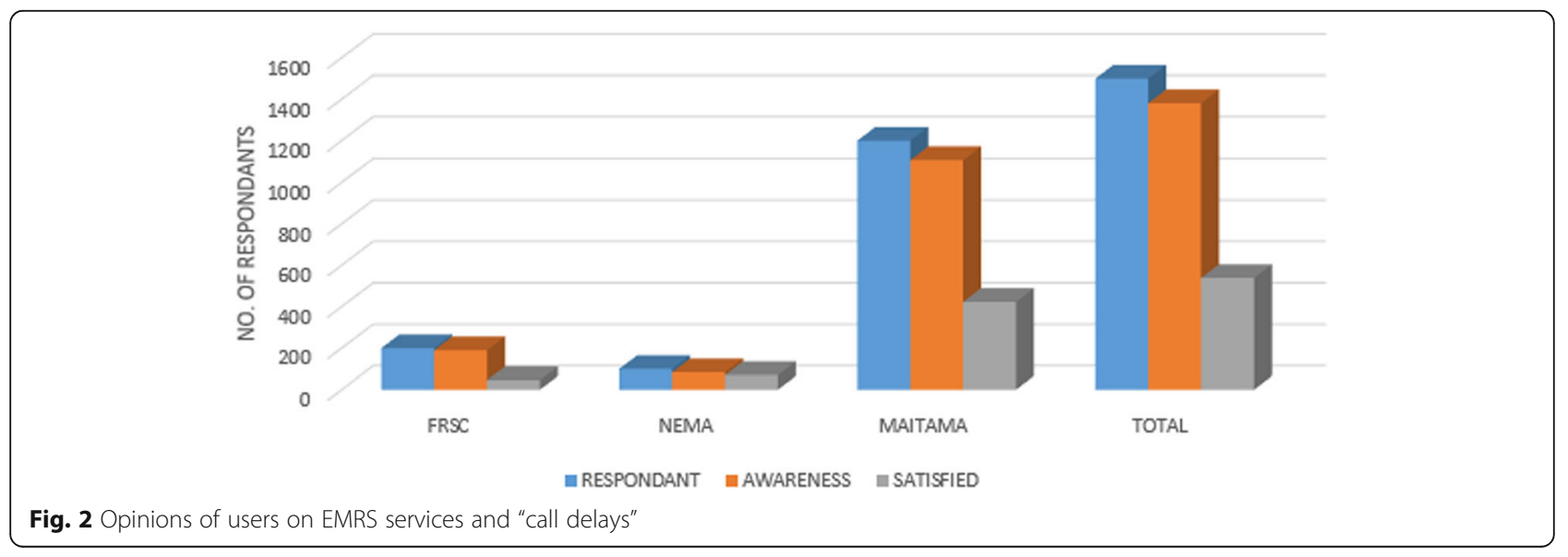


aid interventions) as measured in this study was generally acceptable to be good ( 15 to $30 \mathrm{~min}$ for MAITAMA and NEMA; it was longer for RTIs as FRSC is frequently rescuing victims outside Abuja city). The delay times were shorter in NEMA and MAITAMA because of better ambulance services. Compared to other Low and Middle Income Countries (LMICs) like Ghana, Bangladesh and other developing countries, the delay ranged between $30 \mathrm{~min}$ to $72 \mathrm{~h}$ [1].

\section{Quality of infrastructure and equipment}

The quality of EMRS of the 3 institutions in Abuja was satisfactory compared to other LMICs like Bangladesh (Dhaka) and Togo [16, 17, 24, 25]. These could be attributed to the establishment of FRSC, NEMA and MAITAMA in the late 1980s. FRSC and NEMA have a unique structure of emergency centres known as "Bay Posts". They are located every $17 \mathrm{~km}$ along major roads in Abuja and other parts of Nigeria. Bay posts are well equipped with basic ambulances, trained staff, security and staff with motorcycles which pave the way in obstructed/congested roads for the ambulances during emergencies. The ambulance services are free of charge. However, Abuja suburb is highly populated and when emergencies occur in these areas, delays due to traffic congestion, bad road networks and poor communications contributed to late arrival at the hospital/health care facility.

\section{Staff skills}

FRSC, NEMA and MAITAMA have trained staff comprising Paramedics, Nurses and Doctors. However, having a skilled team does not equate the existence of a high quality EMRS system. Regular on-the-job-training is needed. As elicited in the 3 EMRS agencies, only $20 \%$ of staff had such a training in the preceding 12 months. The attitude and behavioral aspects of the various EMRS staff of the 3 organization need to be addressed as many EMRS victims complained about unfriendly staff behaviour.

\section{Limitation of the study}

One limitation of this study was that those who died during transport to the hospital or at the RTIs scene could not be analyzed separately. Secondly, the three EMRS organizations are not the only agencies in Abuja that offer emergency services. Other emergency medical rescue institutions, such as the Fire Services, the Red Cross, the Federal Civil Service Defense Corps and other private EMRS, need to be assessed and included in future studies.

\section{Conclusions}

The outcome of acute illness or injury is strongly influenced by early recognition of its severity, fast activation of a call centre, rapid arrival of first aid and the fast transport to clinical care. Since most emergencies start at home, any system to promote the early recognition of emergency conditions should be based in the community. The study established that ambulances services are often out of reach for rural and suburb inhabitants. There is limited information on the ability of lay persons and community health workers to recognize and deal with life-threatening emergency conditions. However, it is reasonable to train individuals at suburbs and rural communities to recognize for instance severe blood loss in a postpartum woman, or breathing difficulty in an infant. Many of the benefits of pre-hospital emergency care could be realized by training community volunteers in simple but vital interventions, e.g. establishing and maintaining a patent airway, controlling external bleeding, and immobilizing fractures by means of local materials and resources $[1,25]$.

EMRS institutions need to have a unique call number. Such numbers should be promoted in the media and in the educational systems. Reducing call times and improving EMRS activities in Abuja will significantly reduce delay times and improve EMRS activities, thereby reducing deaths and disabilities.

\section{Abbreviations}

A\&E: Accident and Emergency; ACLS: Advanced Cardiac Life; ATLS: Advanced Trauma Life Support; BLS: Basic Life Support; BSF: Bjorn Steiger Foundation; CFR: Case Fatality Rate; CVD: Cardiovascular Diseases:; DALYS: DisabilityAdjusted Life-Years; EMRS: Emergency Medical and Rescue Services; FGD: Focus Group Discussion; FRSC: Federal Road Safety Commission; ICU: Intensive Care Unit; LMICs: Low and Middle Income Countries; NCD: Non-communicable Diseases;; NEMA: National Emergency Management Agency; RTI: Road Traffic Injury; WHO: World Health Organization

\section{Acknowledgements}

We wish to express our immense gratitude to staff of Federal Medical Centre Keffi, Zankli Medical Centre Abuja, Nigeria, Staff of NEMA, FRSC, and MAITAMA. We also very grateful to Dr. George Norwood (Vice-President, BSF) of Bjorn Steiger Stiftung foundation and all staff of the foundation, Including Mr. Pierre Steiger (President, BSF) and Von Beesten (International Project Coordinator, BSF) for their support/funding of the research project.

\section{Ethical approval and consent to participate}

The research study was conducted in compliance with the ethical principles of the Nuremberg Code and the Declaration of Helsinki (BMJ, 1996; WHO, 2001). The research protocol was submitted and approved by the Ethical Committee of the University of Freiburg (approval number 171/17) which was accepted by the Nigerian authorities. Written informed consent was obtained from all study participants.

\section{Authors' contributions}

PA: Design the project, collected the data, and wrote the manuscript. AK: Design the study, supervised the entire process, and contributed to writing of the manuscript and statistical analysis.

PAl: Contributed to statistical analysis and took part in the data collection and participated in all phases of the work, contributed to writing of the manuscript. 


\section{Funding}

This work was funded by Björn Steiger Foundation, Germany. The organization provided the funds used for carrying out the research project.

\section{Availability of data and materials}

Data is not restricted, data are contained in the manuscript.

\section{Consent for publication}

Not applicable.

\section{Competing interests}

The authors declare that they have no competing interests.

\section{Author details}

${ }^{1}$ Centre for Medicine \& Society (Global Health), University Medical Centre Freiburg, 79014 Freiburg, Germany. ${ }^{2}$ Institute of Human Virology, University Medical Centre Freiburg, Freiburg, Germany. ${ }^{3}$ Department of Paediatrics, Zankli Medical Centre, Abuja, Nigeria.

Received: 13 February 2019 Accepted: 14 November 2019

Published online: 05 December 2019

\section{References}

1. World Health Report. Reducing risks, promoting healthy life. Geneva: WHO; 2002.

2. Fabamwo AO, Okonufua. An assessment of policies and programs for reducing maternal mortality in Lagos state, Nigeria. Migrant Education Comprehensive Needs Assessment Toolkit; A Tool for State Migrant Directors Summer 2012. Afr J Reprod Health (Special Issue). 2010;14(3):63.

3. Kobusingye O, Guwatudde D, Owor G, Lett RR. Citywide trauma experience in Kampala, Uganda: a call for intervention. Injury Prevent. 2002;8:133-6.

4. Menizibeya Osain. 2011. Migrant Education Comprehensive Needs Assessment Toolkit; A Tool for State Migrant Directors Summer 2012. The Nigerian health care system: need for integrating adequate medical intelligence and surveillance systems. J Pharm Bioallied Sci.

5. Oludara M, Idowu O, Ibrahim N, Mustafa I, Ajani A, Balogun R, Solagberu B. Emergency medical services outcome assessment in Lagos, Nigeria: review of cases of "brought in dead" patients. Maced J Med Sci. 2014. https://doi. org/10.3889/MJMS.1857-5773.2014.0392.

6. Obala Foundation, Evaluation of emergency medical systems in 3 major Nigerian cities 2015; www.obalafoundation.org.

7. Oyesola, R. Shehu, D., Ikeh,A.T. Maru. I 1997. "Improving emergency obstetric Care at a State Referral Hospital, Kebbi state, Nigeria." Int J Gynecol Obstet 59 (Suppl. 2): S75-S81.

8. Ali J, Adam R, Gana TJ, Williams. Trauma Patient Outcome after the Prehospital Trauma Life Support Program. J Trauma. 1997:42(6):1018-21 discussion: 1021-22

9. Ali J, Adam R, Josa D, Pierre I, Bedsaysie H, West U. Effect of basic prehospital trauma life support program on cognitive and trauma management skills. World J Surg. 1998;22(12):1192-6.

10. Ande B, Chiwuzie J, Akpala W, Oronsaye A, Okojie O, Okolocha C. Improving Obstetric Care at the District Hospital, Ekpoma, Nigeria. Int J Gynecol Obstet. 1997:59(Suppl):S47-53.

11. Ihekweazu C. Nigeria: in dire need of an emergency medical service: Health; 2014

12. IOM. Migration in Nigeria - A Country Profile. 2014

13. Office of Migrant Education. New Directors Orientation. 2001.

14. Road Accidents in Nigeria, Analysis and Discussion by Adeyemi Adedokun, 2016

15. Shehu D, Ikeh AT, Kuna MJ. Mobilising Transport for Obstetric Emergencies in Northwestern Nigeria. Int J Gynecol Obstet. 1997;59(Suppl. 2):S17-80.

16. Solagberu B.A., Oluwadiya KS. Olakulehin A.O., Olatoke S. A, Olasinde A.A., Komolafe E.O.K., Kolawole I.K. 2005. Pre-hospital care of the injured in south western Nigeria: a hospital based study of four tertiary level hospitals in three states. Annu Proc Assoc Adv Automot Med 2005; 49: 93-100.

17. Weisman SM, Graham DY. Evaluation of the benefits and risks of low-dose aspirin in the secondary prevention of cardiovascular and cerebrovascular events. Arch Intern Med. 2002;162:2197-202.

18. Altintas KH, Bilir N, Tuleylioglu M. Costing of an ambulance system in a developing country, Turkey: costs of Ankara emergency aid and rescue services' (EARS) ambulance system. Eur J Emerg Med. 1999;6:355-62.
19. Andrews CN, Kobusingye OC, Lett RR. Road traffic accident injuries in Kampala. East Afr Med J. 1999;76(3):189-94.

20. WHO (World Health Organization). Management of the Child with Serious Infection or Severe Malnutrition: Guidelines for Care at the First Referral Level in Developing Countries. Integrated Management of Childhood IIIness, Department of Child and Adolescent Health and Development,WHO, Geneva; 2000. Uchenna Anebonam, Chinedu Okoli, Pius Ossai, Olayinka llesanmi,Patrick Nguku, Peter Nsubuga, Ahmed Abubakar, Akin Oyemakinde. Trends in road traffic accidents in Anambra State, South Eastern Nigeria: need for targeted sensitization on safe roads. The Pan African Medical Journal. 2019;32 (Supp 1):12. https://doi.org/10.11604/pamj.supp.2019.32.1. 13285

21. National population commission (NPC). Bulletin of the Nigeria Population Commission. 1996

22. Ogunnaike Adewale Adeyemi and Adewole D.A. 2017. Risk Factors of Road Traffic Accidents (RTAs) among Commercial Inter-State Drivers in Lagos State, Nigeria. Global Journal of Medical Research, 17-5 [S.I.], oct. 2017. Salinas, Cinthia, Ed.; Franquiz, Maria E., Ed.Scholars in the Field: The Challenges of Migrant Education.AEL, Inc., Charleston, WV.; ERIC Clearinghouse on RuralEducation and Small Schools, Charleston, WV. Institute of Education Sciences (ED), Washington, DC.ISBN-1-891677-2332004-00-00. Available https://medicalresearchjournal.org/index.php/ GJMR/article/view/1404

23. Ali J, Adam R, Butler AK, Chang H, Howard M, Gonsalves D. Trauma outcome improves following advanced trauma life support (ATLS) program in a developing country. J Trauma. 1993:34:890-9.

24. Mock CN, Tiska M, Adu-Ampofo M, Boakye G. Improvements in Prehospital trauma Care in an African Country with no formal emergency medical services. J Trauma. 2002;53(1):90-7.

25. Mock CN, Jurkovich GJ, nii-Amon-Kotei D, Arreola-Risa C, Maier RV. Trauma Mortality Patterns in Three Nations at Different Economic Levels: Implications for Global Trauma System Development. J Trauma. 1998;44(5): 804-12

\section{Publisher's Note}

Springer Nature remains neutral with regard to jurisdictional claims in published maps and institutional affiliations.
Ready to submit your research? Choose BMC and benefit from:

- fast, convenient online submission

- thorough peer review by experienced researchers in your field

- rapid publication on acceptance

- support for research data, including large and complex data types

- gold Open Access which fosters wider collaboration and increased citations

- maximum visibility for your research: over $100 \mathrm{M}$ website views per year

At $\mathrm{BMC}$, research is always in progress.

Learn more biomedcentral.com/submissions 